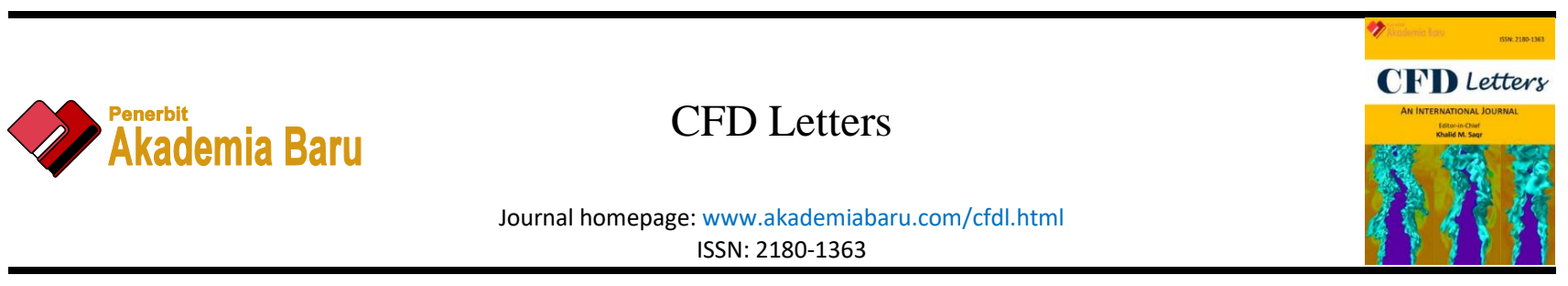

\title{
Development of Performance Correlations using ACFD Method for 2-D Curved Diffuser
}

\author{
Muhammad Zahid Firdaus Shariff ${ }^{1}$, Normayati Nordin ${ }^{1,}$, , Lim Chia Chun ${ }^{1}$, Shamsuri Mohamed \\ Rasidi $^{1}$, Raudhah Othman ${ }^{1}$, Sharifah Adzila ${ }^{1}$ \\ 1 Faculty of Mechanical and Manufacturing Engineering, Universiti Tun Hussein Onn Malaysia, 86400 Batu Pahat, Johor, Malaysia
}

ARTICLE INFO ABSTRACT

\section{Article history:}

Received 20 June 2020

Received in revised form 19 August 2020

Accepted 24 August 2020

Available online 30 August 2020

\section{Keywords:}

2-D curved diffuser; angle of turn; pressure recovery coefficient; flow uniformity; Asymptotic Computational Fluid Dynamics (ACFD)

\begin{abstract}
Diffuser is a fluid mechanical device which allows the recovery of pressure energy from the fluid flow on the outlay of kinetic energy. Performance of turning diffuser is evaluated primarily by pressure recovery coefficient, $C_{p}$ and flow uniformity, $\sigma_{\text {out }}$. The varying of geometrical and operating parameters could alter the performance of the diffuser. Hence, this study aims to investigate the effect of angle of turn, $\phi$ on 2-D curved diffuser performance and to develop performance correlations. The angle of turn was varied from $30^{\circ}$ to $180^{\circ}$. The evaluation for performance of the curved diffusers was done by using ANSYS Fluent with the most appropriate turbulence model of Reynolds Stress Model (RSM) added with enhanced wall treatment of $y^{+}=1.0$. Performance correlations in terms of pressure recovery and flow uniformity were developed by implementing Asymptotic Computational Fluid Dynamics (ACFD) technique. Pressure recovery of the curved diffusers showed a declining pattern by approximately $79.5 \%$ while flow uniformity shows higher distortion up to $52.6 \%$ with the increase of angle of turn from $30^{\circ}$ to $180^{\circ}$. Hence, it has been proven that the increase of angle of turn has affected the performance of curved diffuser significantly. The ACFD performance correlations has provided acceptable deviations to both CFD and experimental results.
\end{abstract}

Copyright $\odot 2020$ PENERBIT AKADEMIA BARU - All rights reserved

\section{Introduction}

Diffuser in its basic form is a straight duct with increased cross section at its outlet. This fluid mechanical device is largely used for its ability to recover pressure energy from the flowing fluid at the expense of fluid kinetic energy [1]. Diffusers are classified by their geometry and parameters which vary for each application. A straight diffuser has no angle of turn whereas a curved diffuser has certain angle of turn [2-3]. Curved diffusers are often introduced in HVAC systems [4], circulating fluidized bed (CFB) system [5], turbines [6-8], and wind tunnel system [9-10]. Many mechanical

\footnotetext{
* Corresponding author.

E-mail address: mayati@uthm.edu.my (Normayati Nordin)
} 
engineering systems such as inlet gates on dams, turbine, ducting systems and compressor crossovers require the installation of diffuser to reduce the fluid flow velocity where the fluid is flowing around the bending ducts [11].

The performance of a diffuser is measured by its ability to recover pressure and the uniformity of flow at its outlet [2]. These indexes are greatly affected by the diffuser's geometry and operating parameters. Previous studies proved that the performance of a curved diffuser is affected by its degree of angle of turn [12]. Due to the curved geometry of a diffuser, the centrifugal force created inside it which results in flow separation would decrease the performance of a curved diffuser [13].

There are currently correlations for curved diffusers such as the work of Nordin et al., [14] and Khong et al., [12] but it is not comprehensive enough to include angle variations from $30^{\circ}$ to $180^{\circ}$. Thus, the objective of the current study is to evaluate numerically the effect of angle of turn on performance and develop the performance correlations of 2-D curved diffuser by varying the angle of turn from $30^{\circ}$ to $180^{\circ}$.

\section{Methodology}

\subsection{Performance Index}

Performance of curved diffuser is defined by the:

(i) Pressure recovery coefficient, $C_{p}$

$C_{p}=\frac{2\left(P_{\text {outlet }}-P_{\text {inlet }}\right)}{\rho V_{\text {inlet }}{ }^{2}}$

Where,

$P_{\text {outlet }}=$ Average static pressure located at diffuser outlet $(\mathrm{Pa})$

$P_{\text {inlet }}=$ Average static pressure located at diffuser outlet $(\mathrm{Pa})$

$\rho=$ Density of air $\left(\mathrm{kg} / \mathrm{m}^{3}\right)$

$V_{\text {inlet }}=$ Inlet air mean velocity $(\mathrm{m} / \mathrm{s})$

(ii) Flow uniformity index, $\sigma_{\text {out }}$

$\sigma_{\text {out }}=\sqrt{\frac{1}{N-1} \sum_{i=1}^{N}\left(V_{i}-V_{\text {out }}\right)^{2}}$

Where,

$\mathrm{N}=$ Number of measurement points

$V_{i}=$ Local outlet air velocity $(\mathrm{m} / \mathrm{s})$

$V_{\text {out }}=$ Mean outlet air velocity $(\mathrm{m} / \mathrm{s})$

\subsection{Modelling}

The 2-D curved diffusers were modelled using Solidworks software. Five models of curved diffusers were constructed by varying the angle of turn, $\phi=30^{\circ}, 90^{\circ}, 120^{\circ}, 150^{\circ}, 180^{\circ}$ as shown in Figure 1. The geometrical parameters of these 2-D curved diffusers are shown in Table 1 which 
$W_{1}$ and $X_{1}$ are the height and width of diffuser inlet, $W_{2}$ and $X_{2}$ are the height and width of diffuser outlet, $r_{i n}$ is the inner circle radius, $L_{i n}$ is the inner wall length, $r_{m}$ is the center circle radius, $L_{m}$ is the center length of the diffuser, and $L_{e}$ is the extended length of diffuser. Figure 2 shows the sketch of $90^{\circ}$ curved diffuser with its construction lines and geometrical parameters.

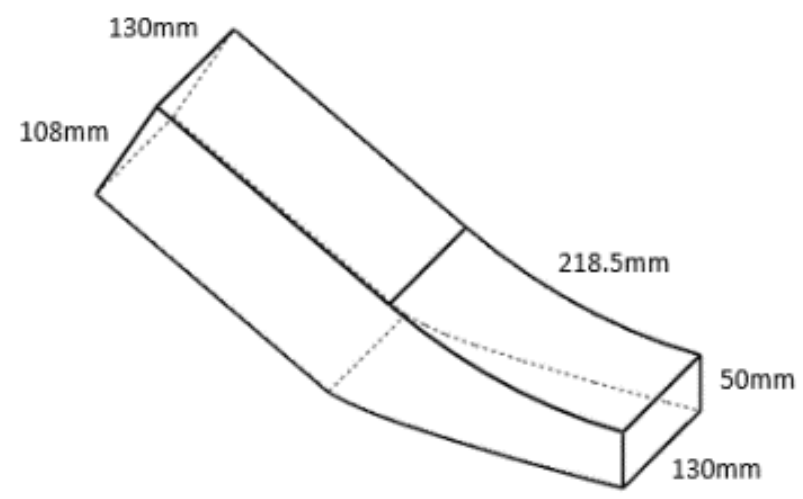

(a)

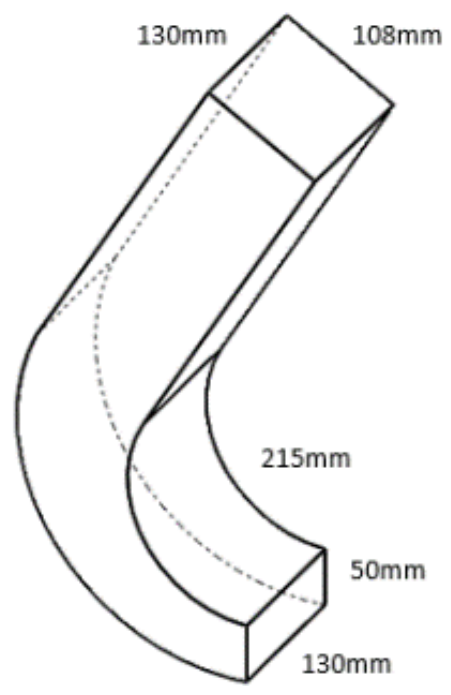

(c)

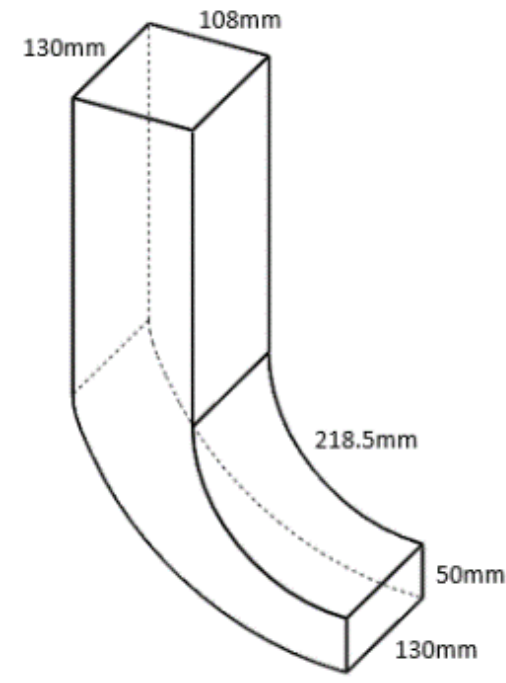

(b)

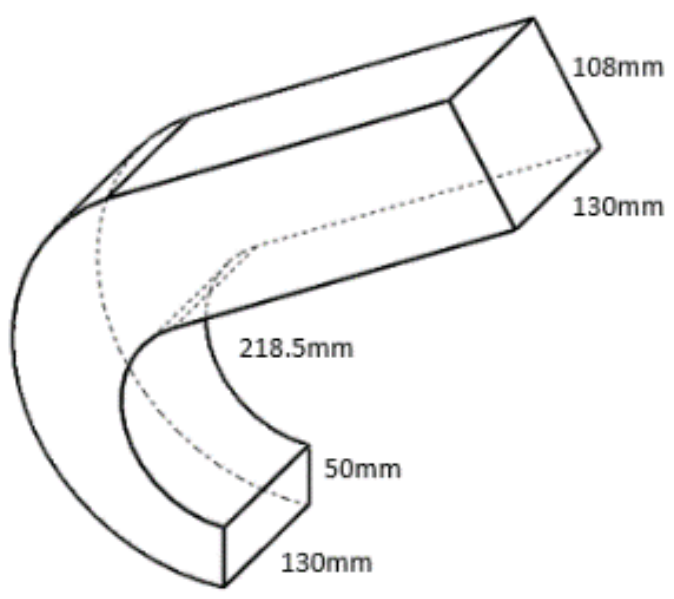

(d)

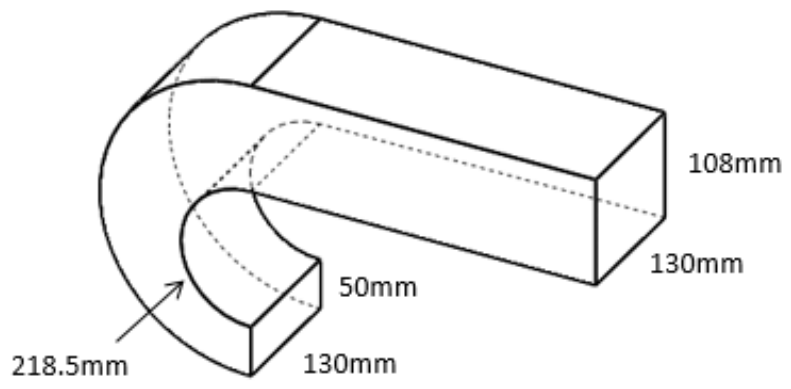

(e)

Fig. 1. 2-D curved diffuser models with turning angle of (a) $\phi_{1}=30^{\circ}$, (b) $\phi_{2}=90^{\circ}$, (c) $\phi_{3}=120^{\circ}$, (d) $\phi_{4}=150^{\circ}$, and (e) $\phi_{5}=180^{\circ}$ 
Table 1

Geometrical parameters of 2-D curved diffuser

\begin{tabular}{llrrrlllll}
\hline$\phi$ & $W_{1}$ & $X_{1}$ & $W_{2}$ & $X_{2}$ & $r_{i n}$ & $L_{\text {in }}$ & $r_{m}$ & $L_{m}$ & $L_{e}$ \\
\hline $30^{\circ}$ & 50 & 130 & 108 & 130 & 417.30 & 218.50 & 755.72 & 239.11 & 239.11 \\
$90^{\circ}$ & 50 & 130 & 108 & 130 & 139.10 & 218.50 & 195.66 & 275.64 & 275.64 \\
$120^{\circ}$ & 50 & 130 & 108 & 130 & 104.33 & 218.50 & 144.95 & 300.56 & 300.56 \\
$150^{\circ}$ & 50 & 130 & 108 & 130 & 83.46 & 218.50 & 123.11 & 321.65 & 321.65 \\
$180^{\circ}$ & 50 & 130 & 108 & 130 & 69.55 & 218.50 & 109.05 & 342.38 & 342.38 \\
\hline
\end{tabular}

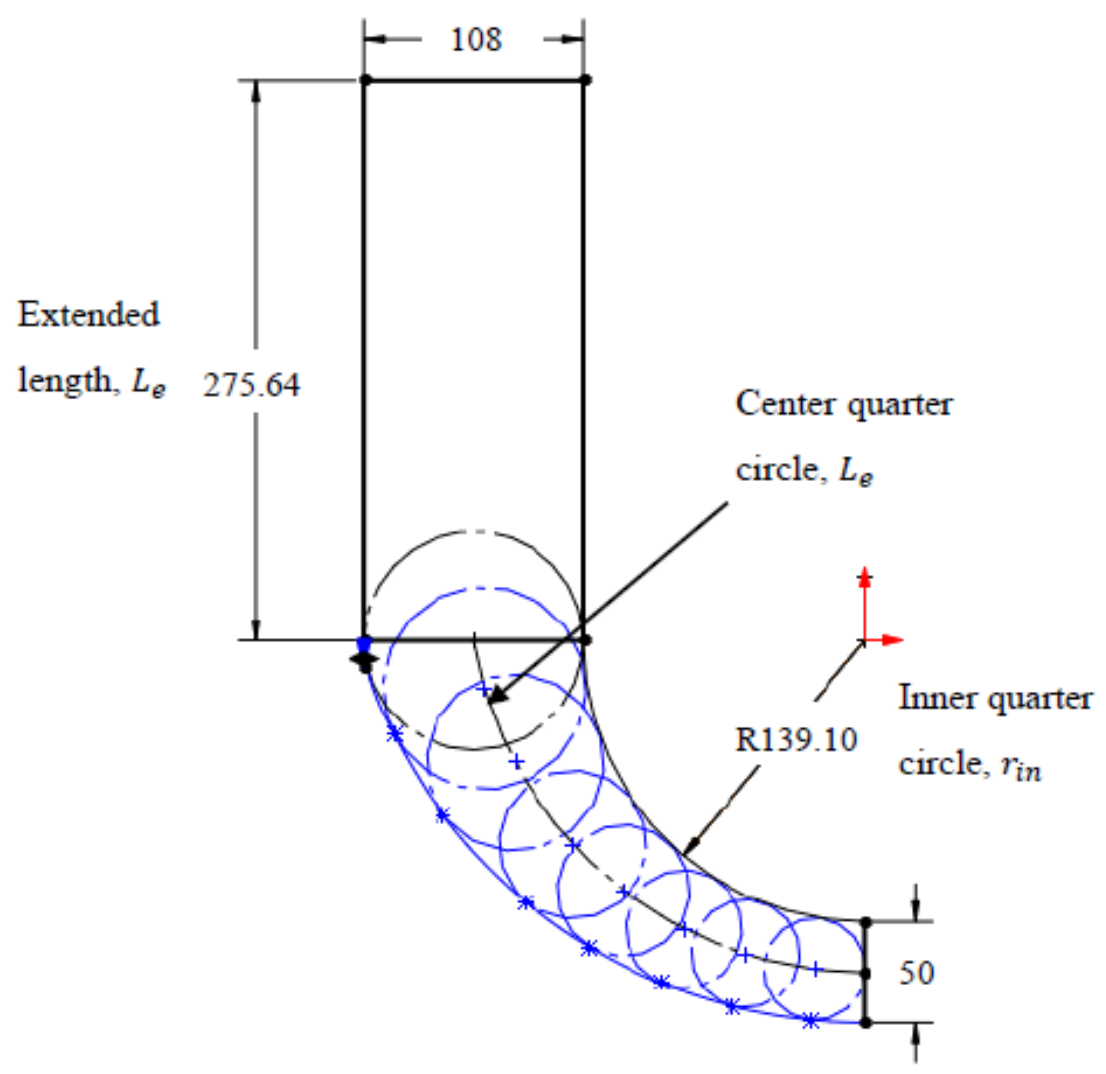

Fig. 2. Sketching and parameters of curved diffuser model

\subsection{Meshing}

Number of node and element could increase by reducing the element size and number of inflation layer. Skewness of the meshing must be less than 0.3. In fact, different meshing method could result in different cell structure. In the current study, the meshing was generated by using the method of Inflation and Multizone. Inflation meshing was implemented to set the first grid point off the wall which is $2.278 \times 10^{-5} \mathrm{~m}$. MultiZone was implemented to set the mapped mesh type into "Hexa" in order to produce Hexahedron cell structure of meshing. Figure 3 shows the mesh generated by using the method of Inflation and Multizone. 


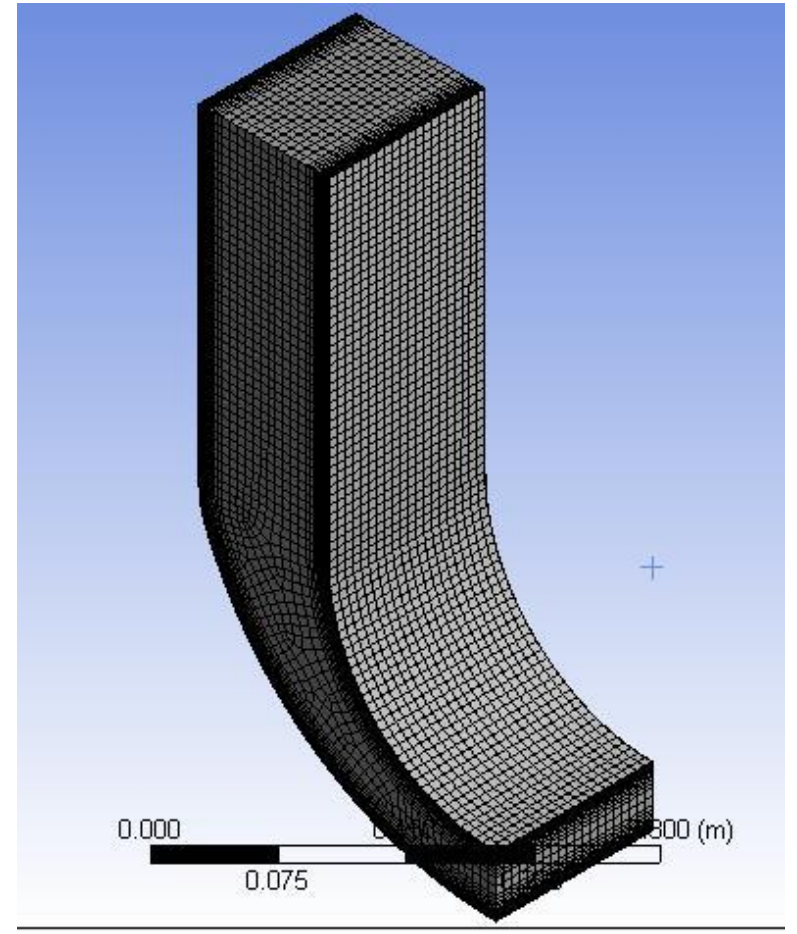

(a)

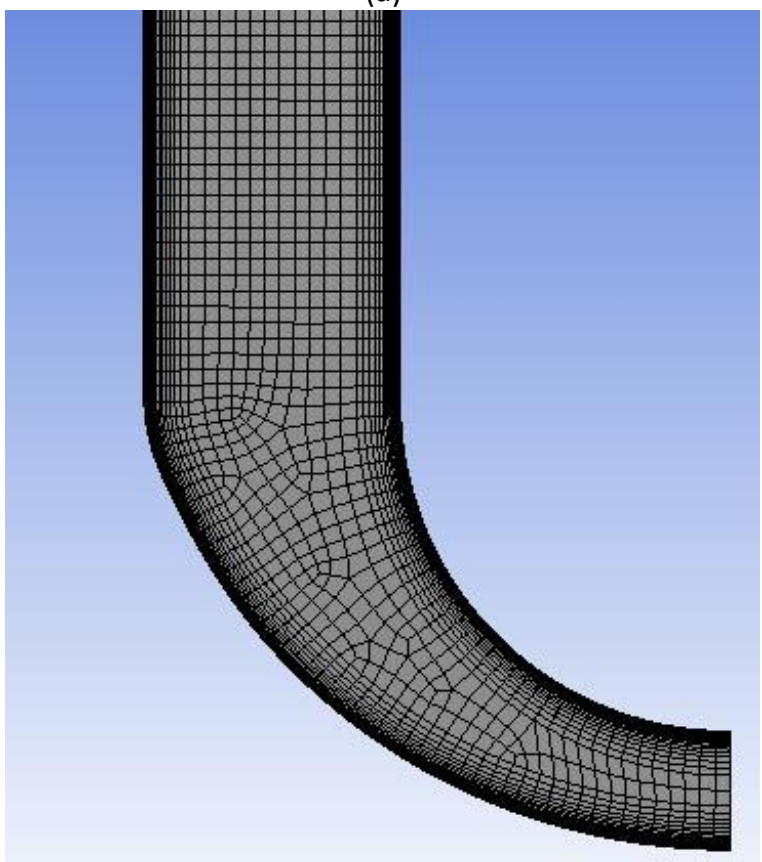

(c)

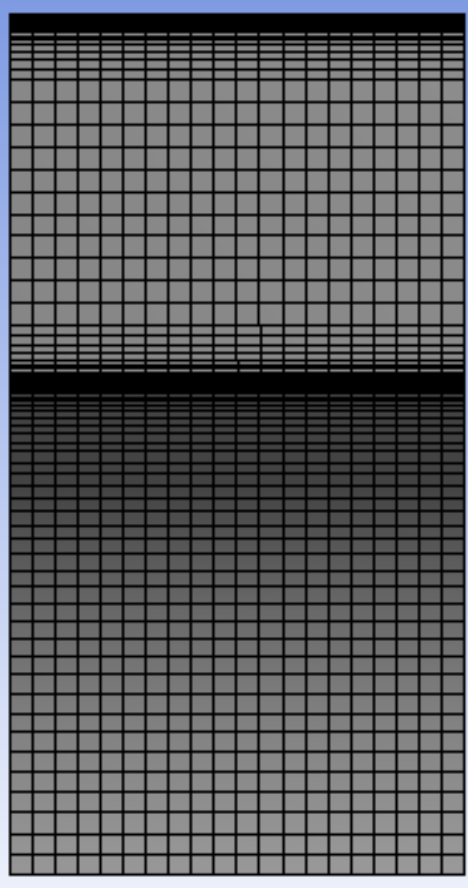

(b)

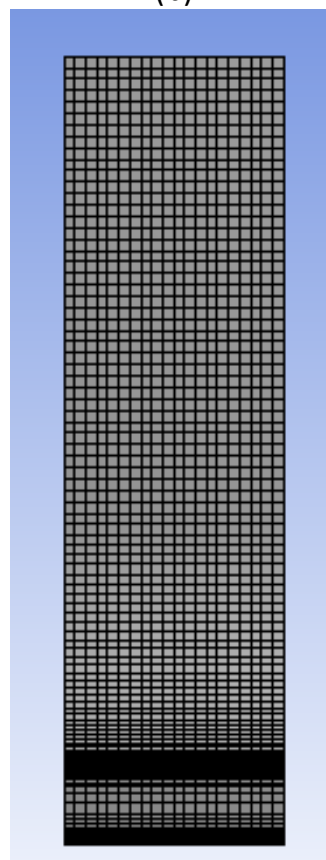

(d)

Fig. 3. Hexahedron cell structure of meshing (a) isometric view, (b) top view, (c) front view and (d) longitudinal view

\subsection{Grid Independency Test}

Grid independency test is a study of determining the appropriate mesh setting for the models created by running the simulation for each increase of nodes and elements. Mesh setting is refined as the number of nodes and elements increase until the simulation result shows an acceptable deviation percentage from two recent mesh setting. After consideration for accuracy and CPU solution time, the mesh with the lower number of nodes and elements between the two mesh 
settings was chosen for the entire study. For this study, the mesh of curved diffuser was generated in Hexahedron cell structure.

\subsection{Boundary Conditions}

The boundary conditions for all boundary zones are set up according to Table 2 . The diffuser inlet is set to have a velocity of $14.25 \mathrm{~m} / \mathrm{s}$, turbulent intensity of $4.0 \%$ and hydraulic diameter $72.22 \mathrm{~mm}$. The diffuser outlet is set to default pressure of 0 (atmospheric pressure). The walls of the diffuser are set to be in no slip shear condition. The working fluid is air with temperature of $30^{\circ} \mathrm{C}$, density $1.164 \mathrm{~kg} / \mathrm{m}^{3}$ and dynamic viscosity of $1.872 \times 10^{-5} \mathrm{~kg} / \mathrm{m}$. s.

\section{Table 2}

Boundary operating conditions for 2-D curved diffuser

\begin{tabular}{lll}
\hline Diffuser Inlet & Boundary type & Velocity-inlet \\
& Velocity magnitude, $V_{\text {in }}(\mathrm{m} / \mathrm{s})$ & $14.25\left(\operatorname{Re}_{\text {in }}=6.385 \times 10^{4}\right)$ \\
& Turbulent intensity, $I_{\text {in }}(\%)$ & 4.0 \\
\multirow{4}{*}{ Diffuser Outlet } & Hydraulic diameter, $D_{h}(\mathrm{~mm})$ & 72.22 \\
\multirow{3}{*}{ Wall } & Boundary type & Pressure-outlet \\
& Pressure $(\mathrm{Pa})$ & 0 (Atmospheric pressure) \\
\multirow{2}{*}{ Working fluid properties } & Boundary type & Smooth wall \\
& Shear condition & No-slip \\
& Working fluid & Air \\
& Temperature $\left({ }^{\circ} \mathrm{C}\right)$ & 30 \\
& Density, $\rho\left(\mathrm{kg} / \mathrm{m}^{3}\right)$ & 1.164 \\
& Dynamic viscosity, $\mu(\mathrm{kg} / \mathrm{m} . \mathrm{s})$ & $1.872 \times 10^{-5}$ \\
\hline
\end{tabular}

\subsection{Governing Equations}

The Reynolds-Averaged Navier-Stokes equation (RANS) is used to solve the analysis for Newtonian and incompressible fluid flow which is shown as following:

Continuity equation:

$\frac{\partial u}{\partial x}+\frac{\partial v}{\partial y}+\frac{\partial w}{\partial z}=0$

$\mathrm{x}$-momentum equation:

$u \frac{\partial u}{\partial x}+v \frac{\partial u}{\partial y}+w \frac{\partial u}{\partial z}=-\frac{1}{\rho} \frac{\partial P}{\partial x}+v\left[\frac{\partial^{2} u}{\partial x^{2}}+\frac{\partial^{2} u}{\partial y^{2}}+\frac{\partial^{2} u}{\partial z^{2}}\right]+\frac{1}{\rho}\left[\frac{\partial\left(-\rho \overline{u^{\prime 2}}\right)}{\partial x}+\frac{\partial\left(-\rho \overline{\left.u^{\prime} v^{\prime}\right)}\right.}{\partial y}+\frac{\partial\left(-\rho \overline{u^{\prime} w^{\prime}}\right)}{\partial z}\right]$

y-momentum equation:

$u \frac{\partial v}{\partial x}+v \frac{\partial v}{\partial y}+w \frac{\partial v}{\partial z}=-\frac{1}{\rho} \frac{\partial P}{\partial y}+v\left[\frac{\partial^{2} v}{\partial x^{2}}+\frac{\partial^{2} v}{\partial y^{2}}+\frac{\partial^{2} v}{\partial z^{2}}\right]+\frac{1}{\rho}\left[\frac{\partial\left(-\rho \overline{\left.u^{\prime} v^{\prime}\right)}\right.}{\partial x}+\frac{\partial\left(-\rho \overline{v^{\prime 2}}\right)}{\partial y}+\frac{\partial\left(-\rho \overline{v^{\prime} w^{\prime}}\right)}{\partial z}\right]$

z-momentum equation:

$u \frac{\partial w}{\partial x}+v \frac{\partial w}{\partial y}+w \frac{\partial w}{\partial z}=-\frac{1}{\rho} \frac{\partial P}{\partial z}+v\left[\frac{\partial^{2} w}{\partial x^{2}}+\frac{\partial^{2} w}{\partial y^{2}}+\frac{\partial^{2} w}{\partial z^{2}}\right]+\frac{1}{\rho}\left[\frac{\partial\left(-\rho \overline{\left.u^{\prime} w^{\prime}\right)}\right.}{\partial x}+\frac{\partial\left(-\rho \overline{\left.v^{\prime} w^{\prime}\right)}\right.}{\partial y}+\frac{\partial\left(-\rho \overline{w^{2}}\right)}{\partial z}\right]$ 


\subsection{Solver}

In order for simulations to have an accurate data, a suitable turbulence model should be chosen from several. Most common turbulence models were applied to determine the performance of turning diffuser namely Standard $k-\varepsilon$ (ske) Turbulence Model, Shear Stress Transport $k-\omega$ (SST $k-$ $\omega)$ model and Reynolds Stress Model (RSM). Detail setting for the simulation of the curved diffusers in ANSYS CFD is shown in Table 3. The simulation applied the pressure-linked equation with semiimplicit method (SIMPLE). The SIMPLE algorithm was derived from the continuity and momentum equation combined in order to derive pressure equation. The Green-Gauss-Cell based was used to occupy the solution for the gradient while QUICK-type scheme was applied for the momentum equations, turbulent dissipation rate equation and turbulent kinetic energy equation. A convergence value of $10^{-5}$ was suggested as the residual error for all the governing equations in this study [15].

Table 3

Detail setting for the simulation of 2-D $90^{\circ}$ curved diffuser in ANSYS Fluent

\begin{tabular}{ll}
\hline $\begin{array}{l}\text { Mesh } \\
\text { Mype of Mesh } \\
\text { Solver method }\end{array}$ & Hexahedron \\
& $\begin{array}{l}\text { Reynolds Stress Model (RSM), Standard } k-\varepsilon \text { (ske), Shear } \\
\text { Stress Transport } k-\omega(\text { SST } k-\omega)\end{array}$ \\
\hline Solution Methods & \\
\hline Solver Scheme & SIMPLE \\
Gradient & Green-Gauss Cell Based \\
Pressure & PRESTO! \\
Momentum & QUICK \\
Turbulent Kinetic Energy & QUICK \\
Turbulent Dissipation Rate & QUICK \\
Reynolds Stresses & First order upwind \\
\hline
\end{tabular}

\subsection{CFD Validation}

The validation work is done by comparing the result from the experimental study by Nordin et al., [2]. The focus of this validation is the pressure recovery performance, flow uniformity and flow structure. The curved diffuser geometry and operating parameters for validation work is shown in Table 4.

Table 4

Parameters of validation case [2]

\begin{tabular}{ll}
\hline Parameter & Magnitude \\
\hline$R e_{\text {in }}$ & $6.382 \times 10^{4}$ \\
$\mathrm{~W}_{2} / \mathrm{W}_{1}$ & 2.16 \\
$\mathrm{Lin}_{\text {in }} / \mathrm{W}_{1}$ & 4.37 \\
$\mathrm{X}_{2} / \mathrm{X}_{1}$ & 1.00 \\
$\varnothing$ & $90^{\circ}$ \\
$C_{p}$ & 0.209 \\
$\sigma_{\text {out }}$ & 2.69 \\
\hline
\end{tabular}

\subsection{ACFD Method}

The performance correlations for 2-D curved diffuser with varying angle of turn from $30^{\circ}$ to $180^{\circ}$ were developed by using the technique of Asymptotic Computational Fluid Dynamics (ACFD). The 
main steps to develop the performance correlation for 2-D curved diffuser using ACFD technique are as follows $[2,12,16]$ :

I. Identifying the dependent and independent variables

II. Linearizing the interconnection between dependent and independent variables

III. Employing the Taylor's series expansion

IV. Resolving convergence points and gradients

V. Substitutes all the constants

$C_{p \text { acfd }}=f\left(\operatorname{Re}_{i n}, W_{2} / W_{1}, L_{\text {in }} / W_{1}, \phi\right)$

$\sigma_{\text {out acfd }}=f\left(\operatorname{Re}_{\mathrm{in}}, \mathrm{W}_{2} / \mathrm{W}_{1}, \mathrm{~L}_{\mathrm{in}} / \mathrm{W}_{1}, \phi\right)$

$\eta\left(\phi_{1}, \phi_{2}, \phi_{3}, \ldots \phi_{n}\right)=\eta_{\text {ref }}+\left(\phi_{1}-\phi_{1 \text { ref }}\right) \frac{\partial \eta}{\partial \phi_{1}}+\left(\phi_{2}-\phi_{2 r e f}\right) \frac{\partial \eta}{\partial \phi_{2}}+\left(\phi_{3}-\phi_{3 r e f}\right) \frac{\partial \eta}{\partial \phi_{3}}+\ldots+\left(\phi_{n}-\right.$ $\left.\phi_{n \text { ref }}\right) \frac{\partial \eta}{\partial \phi_{n}}$

Where,

$\eta=$ dependent variables $\left(\mathrm{C}_{\mathrm{p}}, \sigma_{\text {out }}\right)$

$\phi_{1}=\left[\frac{R e_{\text {in }}}{R e_{\text {in ref }}}\right]^{a}, \phi_{2}=\left[\frac{L_{\text {in }} / W_{\text {in }}}{L_{\text {in }} / W_{1 \text { ref }}}\right]^{b}, \phi_{3}=\left[\frac{W_{2} / W_{1}}{W_{2} / W_{1 \text { ref }}}\right]^{c}$, and $\phi_{4}=\left[\frac{\phi}{\phi_{\text {ref }}}\right]^{d}$

Where $\phi_{1}, \phi_{2}, \phi_{3}$ and $\phi_{4}$ represent the dimensionless independent group.

\section{Result and Discussion}

\subsection{Grid Independency Test}

The grid independence test was conducted by observing the pressure recovery, $C_{p}$ value for the 2-D curved diffuser as the mesh is being refined in stages. The acceptable deviation of $C_{p}$ between mesh settings is $5 \%$. Thus, the mesh with lower deviation is chosen as the optimum mesh setting and used throughout this study. Table 5 shows the deviation between mesh 5 and 6 have a deviation for $C_{p}$ of $6.63 \%$ while mesh 6 and 7 have a deviation of 1.32\%. Mesh 7 with 363,965 elements was chosen as the optimum mesh setting instead of mesh 8 as the deviation between them is too small with increasing the solution time.

\section{Table 5}

Grid independency test for $90^{\circ}$ 2-D curved diffuser

\begin{tabular}{llll}
\hline Mesh & Elements & Pressure Recovery, $C_{p}$ & Deviation, \% \\
\hline 1 & 107640 & 0.0447 & 53.58 \\
2 & 158640 & 0.0963 & 39.43 \\
3 & 213975 & 0.1590 & 11.86 \\
4 & 262110 & 0.1804 & 10.11 \\
5 & 304224 & 0.2007 & 6.92 \\
6 & 327162 & 0.2156 & 6.63 \\
7 & 363965 & 0.2309 & 1.32 \\
8 & 386820 & 0.2340 & - \\
\hline
\end{tabular}




\subsection{CFD Validation Result}

In order to obtain an accurate and reliable data, the result from CFD must undergo validation process with an experimental data, which in this study is the data from the experimental work by Nordin et al., [2]. The values of pressure recovery, $C_{p}$ obtained from the CFD simulations using three turbulence models are compared with the experimental data in Table 6 . The turbulence model chosen to be used for intensive simulation is Reynolds Stress Model (RSM) which produced the result with the least and acceptable deviation of $10.47 \%$ compared to turbulence model Standard $k-\varepsilon$ and SST $k-\omega$. Figure 4 shows the velocity profile for the three turbulence models while Figure 5 shows the flow structure of experimental and RSM simulation result.

\section{Table 6}

Deviation of pressure recovery, $C_{p}$ for different solver model with experimental result

\begin{tabular}{lll}
\hline Turbulence Model & Pressure recovery, $C_{p}$ & Deviation (\%) \\
\hline Standard $k-\varepsilon$ & 0.2760 & 32.06 \\
SST $k-\omega$ & 0.1744 & 16.56 \\
RSM & 0.2309 & 10.47 \\
Experiment & 0.2090 & - \\
\hline
\end{tabular}

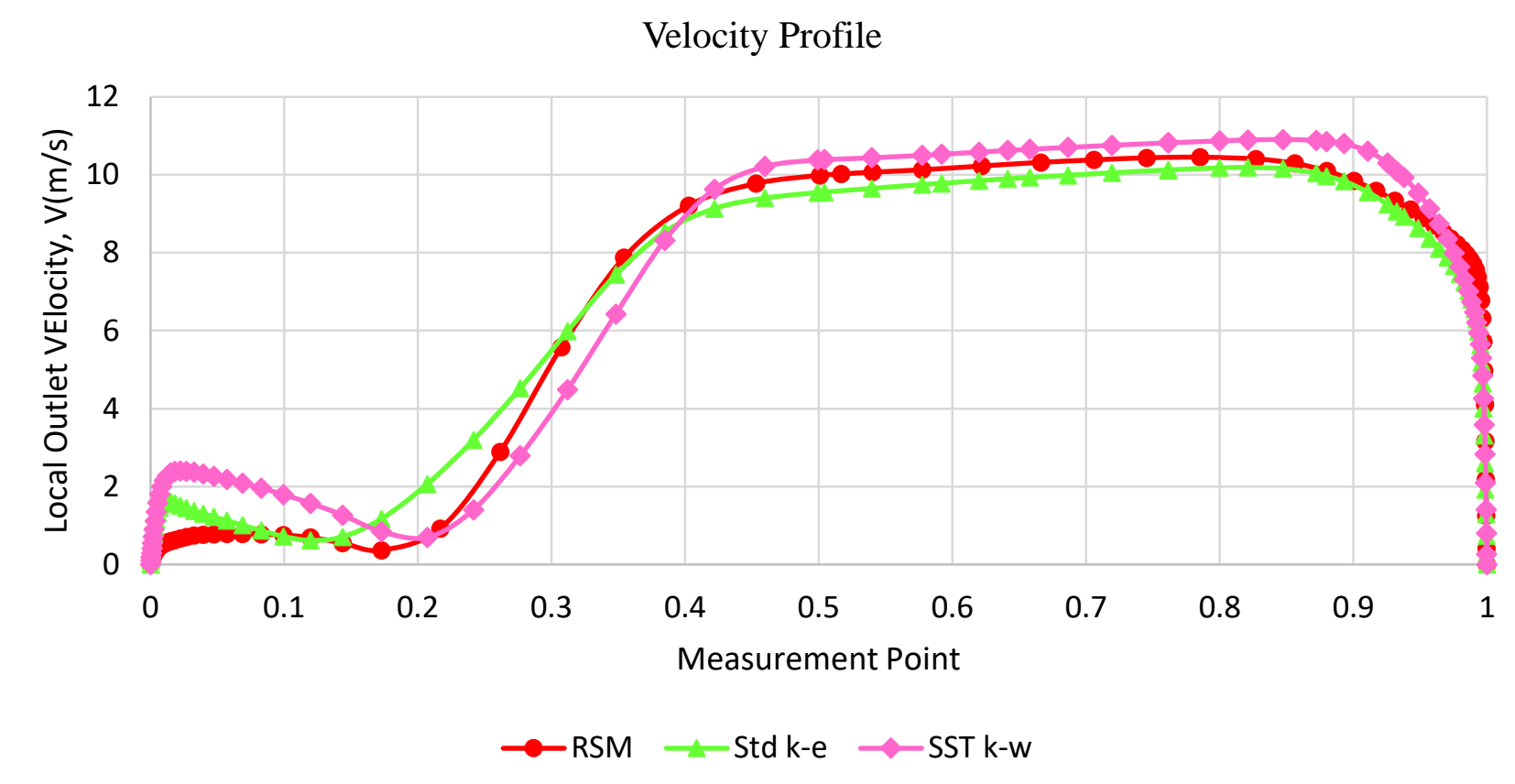

Fig. 4. Velocity profile for different solver models 


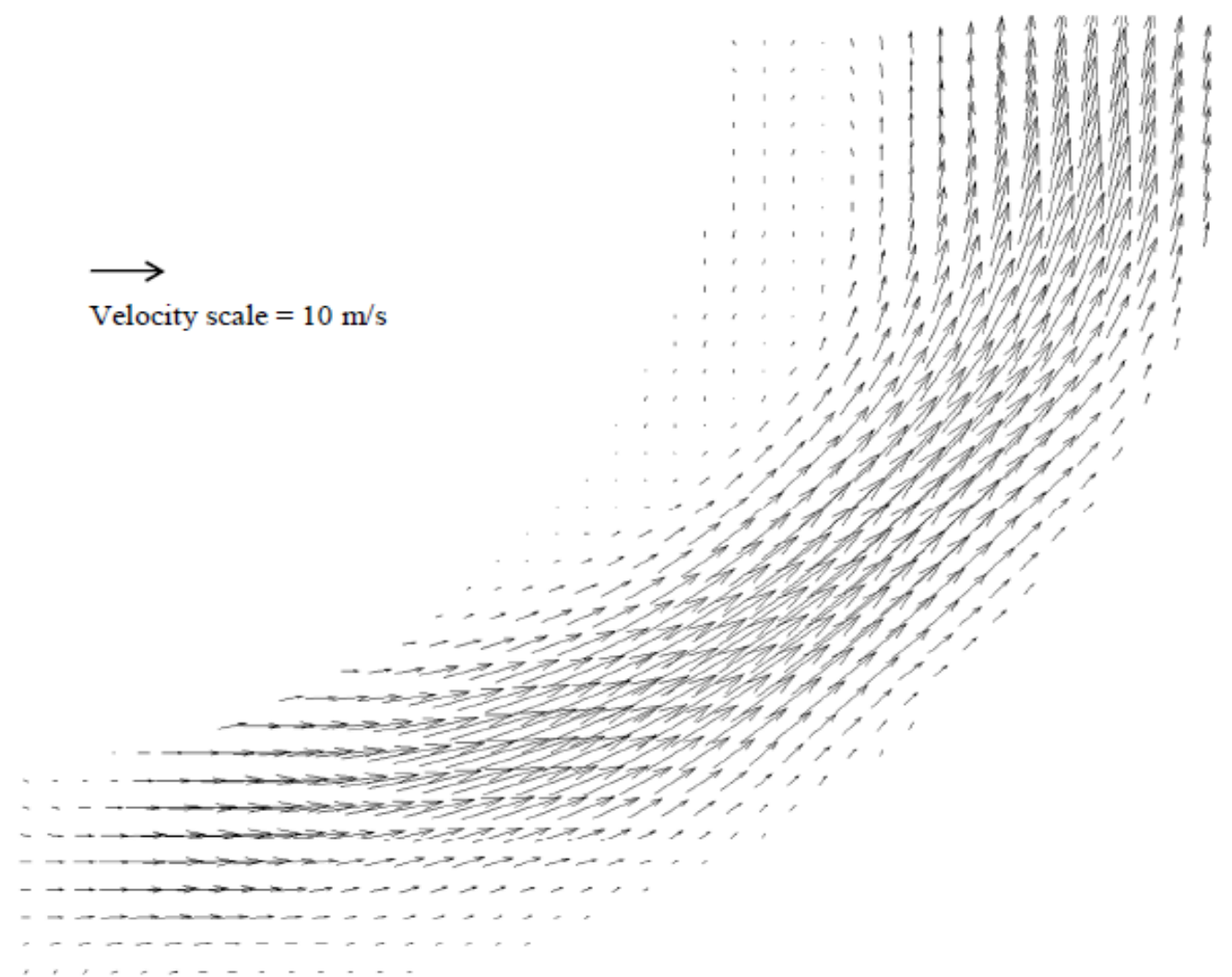

(a)
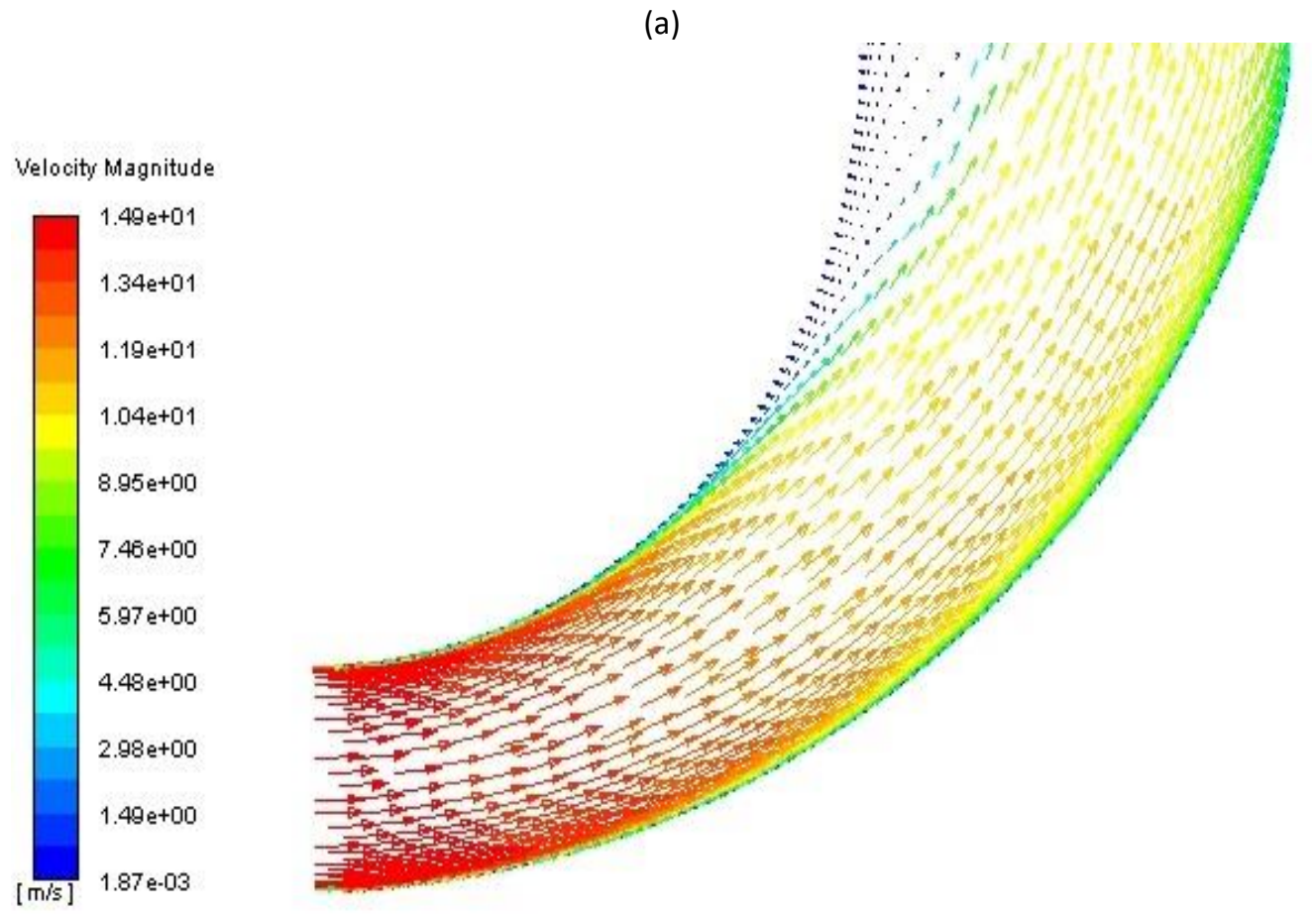

(b)

Fig. 5. Flow structure from (a) experimental result [2] and (b) RSM simulation result

\subsection{Effect of Angle of Turn, $\phi$}

The results of pressure recovery, $C_{p}$, flow uniformity, $\sigma_{\text {out }}$, and flow separation point, $S$ obtained from intensive simulation on the 2-D curved diffuser with varying angle of turn, $\phi$ is shown in Table 
7. Higher value of $C_{p}$ and lower value of $\sigma_{\text {out }}$ indicates higher performance. The results prove that by increasing the angle of turn from $30^{\circ}$ to $180^{\circ}$, the $C_{p}$ decreases by approximately $79.5 \%$ and flow uniformity distorted by approximately $52.6 \%$.

Figure 6 shows the velocity profiles for each 2-D curved diffuser from $30^{\circ}$ to $180^{\circ}$ angle of turn. The velocity profile gets less uniform and the flow concentrates more at the outer wall as the angle of turn increases. Due to the diffuser's geometry, the centrifugal force affects the fluid flow to lean towards the outer wall while creating flow separation at the inner wall. Figure 7 shows the flow separation caused a reverse flow near the inner wall of the diffuser. The separation point occurred nearer to the inlet of the diffuser as the angle of turn increases.

\section{Table 7}

Performance of 2-D curved diffuser by varying the turning angle from $30^{\circ}$ to $180^{\circ}$

\begin{tabular}{llll}
\hline Turning angle, $\phi$ & Pressure recovery, $C_{p}$ & Flow uniformity, $\sigma_{\text {out }}$ & Flow separation point, S \\
\hline $30^{\circ}$ & 0.464 & 3.235 & - \\
$90^{\circ}$ & 0.231 & 3.823 & $0.646 L_{1} / W_{1}$ \\
$120^{\circ}$ & 0.274 & 3.668 & $0.578 L_{1} / W_{1}$ \\
$150^{\circ}$ & 0.109 & 4.936 & $0.404 L_{1} / W_{1}$ \\
$180^{\circ}$ & 0.095 & 4.741 & $0.391 L_{1} / W_{1}$ \\
\hline
\end{tabular}

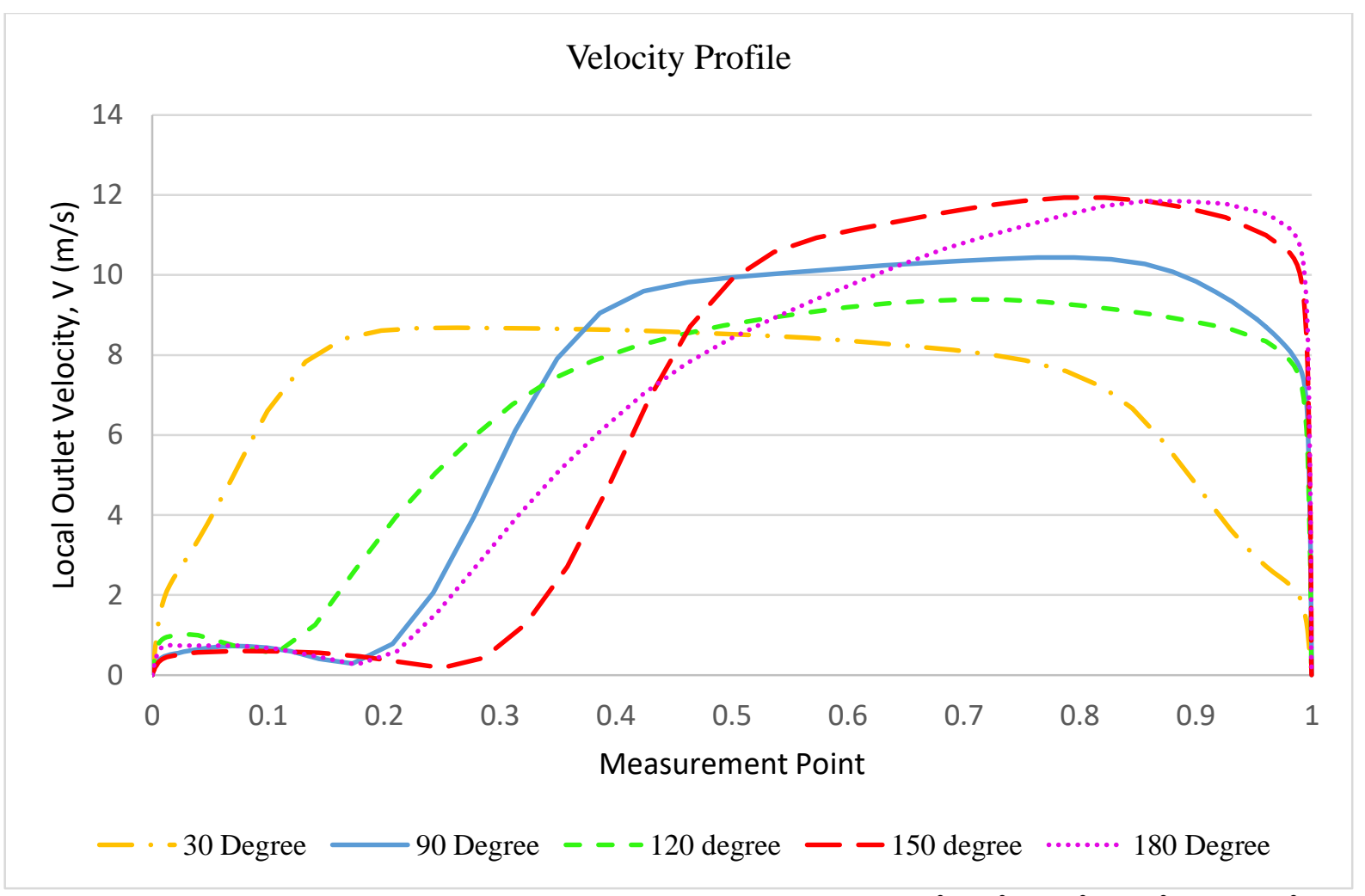

Fig. 6. Velocity profile of $2-\mathrm{D}$ curved diffuser for turning angles $30^{\circ}, 90^{\circ}, 120^{\circ}, 150^{\circ}$ and $180^{\circ}$ 


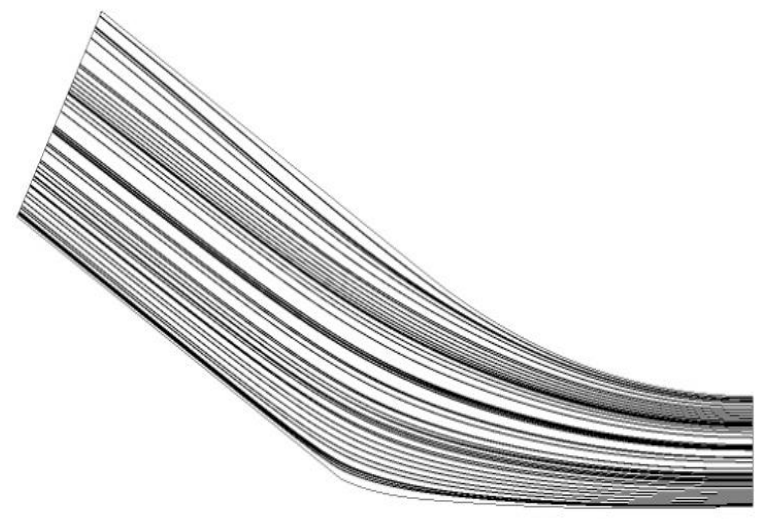

(a)

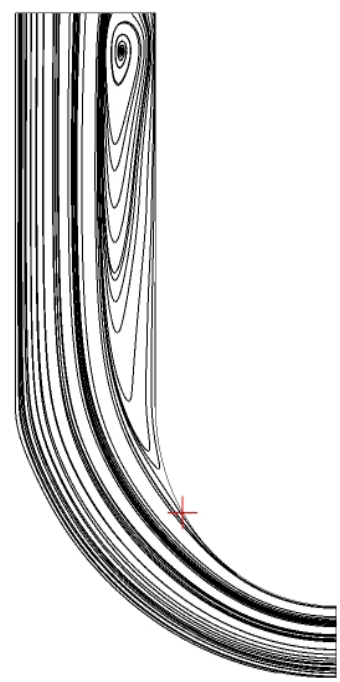

(c)

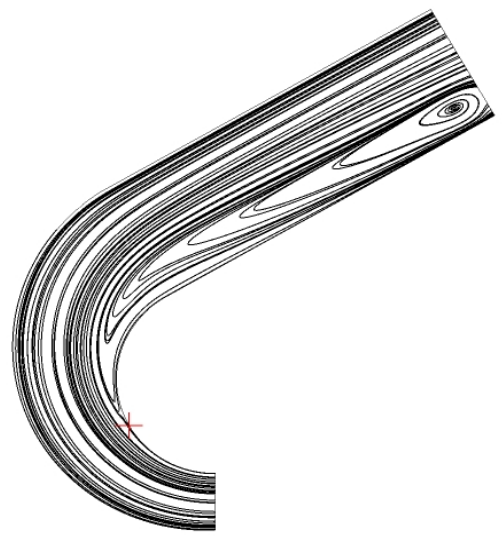

(b)

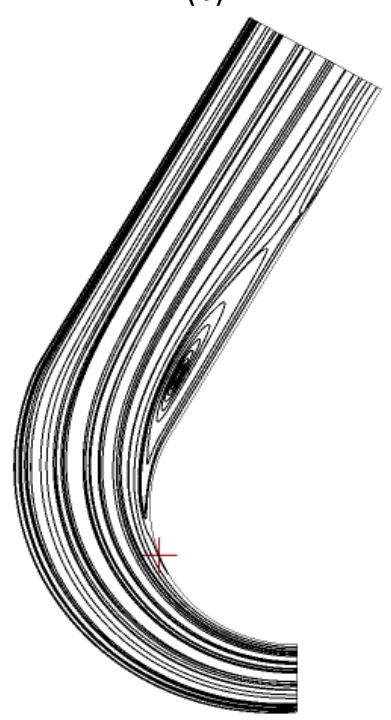

(d)

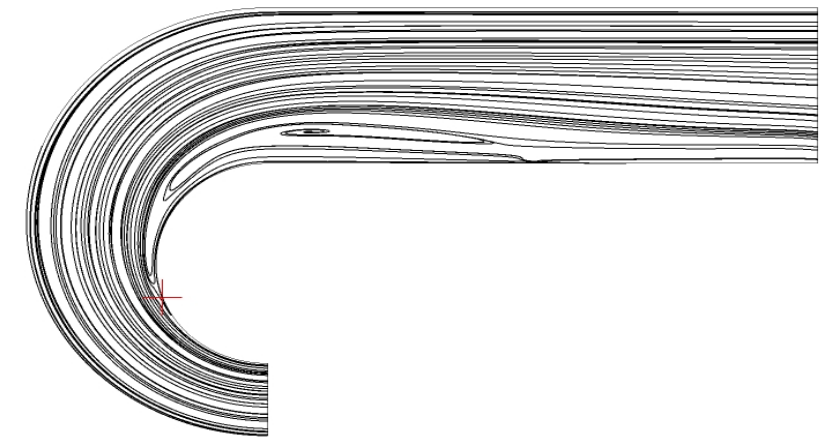

(e)

Fig. 7. Flow separation of 2-D curved diffuser for turning angles (a) $30^{\circ}$,(b) $90^{\circ}$, (c) $120^{\circ}$,(d) $150^{\circ}$ and (e) $180^{\circ}$

\subsection{Development of ACFD Performance Correlations for 2-D Curved Diffuser}

Correlation of two-dimensional (2-D) turning diffuser, $C_{p \text { acf }}$ are develop by employing Taylor series expansion.

$$
\begin{aligned}
C_{p a c f d}= & C_{p r e f}+\left(\emptyset_{1}-\emptyset_{1 r e f}\right) \frac{\partial C_{p}}{\partial \emptyset_{1}}+\left(\emptyset_{2}-\emptyset_{2 r e f}\right) \frac{\partial C_{p}}{\partial \emptyset_{2}}+\left(\emptyset_{3}-\emptyset_{3 r e f}\right) \frac{\partial C_{p}}{\partial \emptyset_{3}} \\
& +\left(\emptyset_{4}-\emptyset_{4 r e f}\right) \frac{\partial C_{p}}{\partial \emptyset_{4}}
\end{aligned}
$$




$$
\emptyset_{1}=\left[\frac{R e_{\text {in }}}{R e_{\text {in ref }}}\right]^{a}, \emptyset_{2}=\left[\frac{L_{\text {in }} / W_{1}}{L_{\text {in }} / W_{1 \text { ref }}}\right]^{b}, \emptyset_{3}=\left[\frac{W_{2} / W_{1}}{W_{2} / W_{1 \text { ref }}}\right]^{c} \text { and } \emptyset_{4}=\left[\frac{\emptyset}{\emptyset_{\text {ref }}}\right]^{d}
$$

Where $\emptyset_{1}, \emptyset_{2}, \emptyset_{3}$ and $\emptyset_{4}$ are dimensionless independent groups.

The values of $a=1, b=1.5, c=2$ and $d=0.4$ were determined in order to fit all the trend-lines in a graph and coincide at point $C_{p \text { ref }}=0.20$ as shown in Figure 8 . The inter-relations of dependent variable of $C_{p}$ with each independent variable were linearized to obtain the best fit straight line.

$\emptyset_{1 \text { ref }}=\left[\frac{R e_{\text {in ref }}}{R e_{\text {in ref }}}\right]^{a}=1.0$

Therefore, $\emptyset_{2 \text { ref }}=\emptyset_{3 \text { ref }}=\emptyset_{4 \text { ref }}=1.0$ as well. $\frac{\partial C_{p}}{\partial \emptyset_{1}}=0.0215, \frac{\partial C_{p}}{\partial \emptyset_{2}}=-0.2998, \frac{\partial C_{p}}{\partial \emptyset_{3}}=-0.013$, and $\frac{\partial C_{p}}{\partial \emptyset_{4}}=-0.5444$ represented the slopes of the corresponding lines.

All the constants obtained are substituted into Eq. (10) yielding,

$$
\begin{aligned}
& C_{\text {pacfd }}=0.20+\left(\left[\frac{R e_{\text {in }}}{R e_{\text {in ref }}}\right]^{1}-1\right) 0.0215-\left(\left[\frac{L_{\text {in }} / W_{1}}{L_{\text {in }} / W_{1 \text { ref }}}\right]^{1.5}-1\right) 0.2998-\left(\left[\frac{W_{2} / W_{1}}{W_{2} / W_{1 \text { ref }}}\right]^{2}-\right. \\
& \text { 1) } 0.013-\left(\left[\frac{\emptyset}{\emptyset_{\text {ref }}}\right]^{0.4}-1\right) 0.5444
\end{aligned}
$$

Where,

$$
R e_{\text {in ref }}=6.382 \times 10^{4}, L_{\text {in }} / W_{1 \text { ref }}=4.37, W_{2} / W_{1 \text { ref }}=1.2 \text { and } \emptyset_{\text {ref }}=90^{\circ}
$$

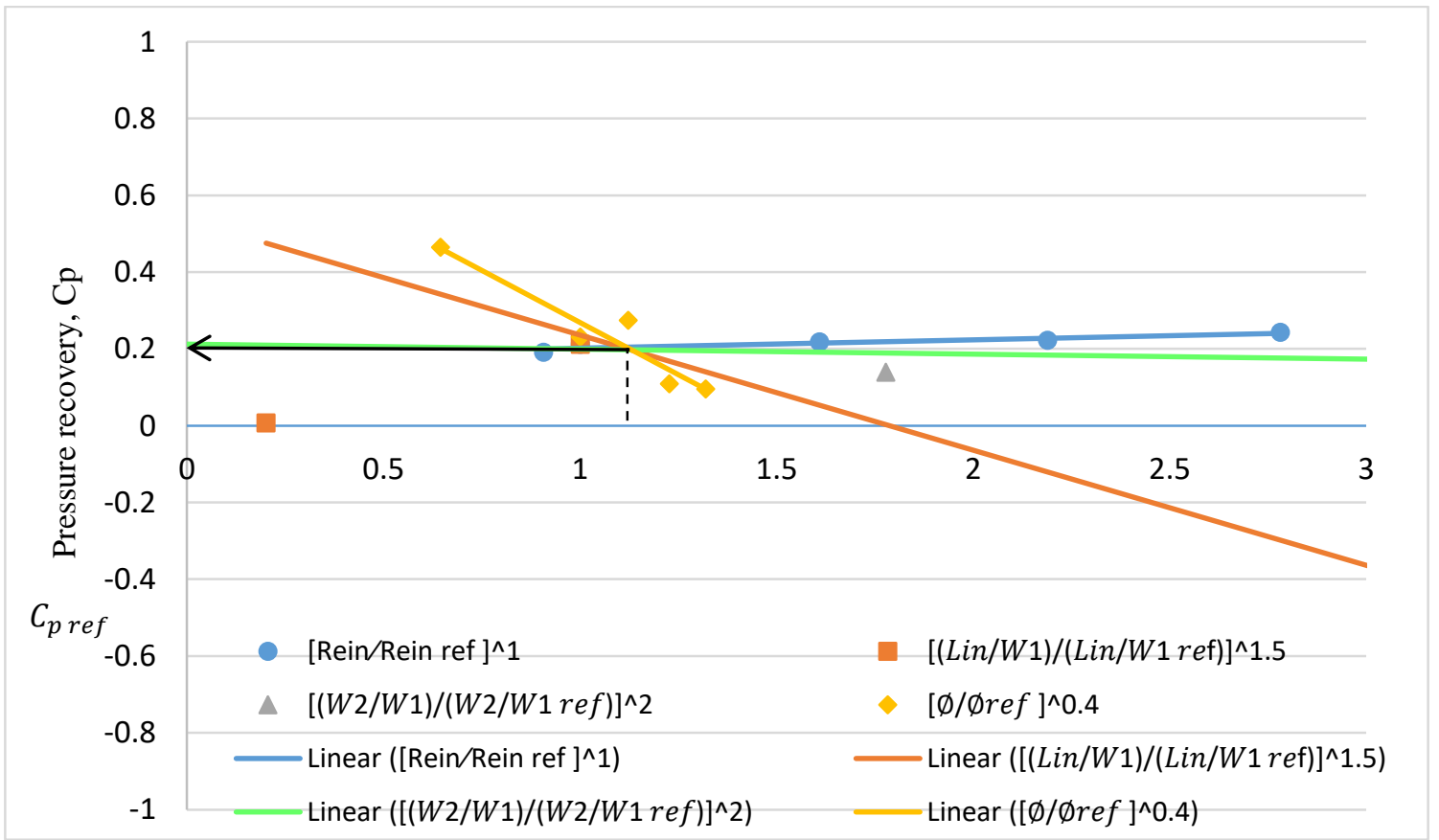

Fig. 8. Outlet pressure recovery, $C_{p}$ of 2-D turning diffuser relatives to $\emptyset_{1}=\left[\mathrm{Re}_{\text {in }} / \mathrm{Re}_{\text {in ref }}\right]^{1}, \emptyset_{2}=$ $\left[\mathrm{L}_{\mathrm{in}} / \mathrm{W}_{1} / \mathrm{L}_{\mathrm{in}} / \mathrm{W}_{1 \text { ref }}\right]^{1.5}, \emptyset_{3}=\left[\mathrm{W}_{2} / \mathrm{W}_{1} / \mathrm{W}_{2} / \mathrm{W}_{1 \text { ref }}\right]^{2}$ and $\emptyset_{4}=\left[\varnothing / \emptyset_{\text {ref }}\right]^{0.4}$ 
The correlation of flow uniformity, $\sigma_{\text {out }}$ for two-dimensional turning diffuser was also developed by applying Taylor series expansion as well.

$$
\begin{aligned}
& \sigma_{\text {out acfd }}=\sigma_{\text {out ref }}+\left(\emptyset_{1}-\emptyset_{1 \text { ref }}\right) \frac{\partial \sigma_{\text {out }}}{\partial \emptyset_{1}}+\left(\emptyset_{2}-\emptyset_{2 \text { ref }}\right) \frac{\partial \sigma_{\text {out }}}{\partial \emptyset_{2}}+\left(\emptyset_{3}-\emptyset_{3 \text { ref }}\right) \frac{\partial \sigma_{\text {out }}}{\partial \emptyset_{3}}+ \\
& \left(\emptyset_{4}-\emptyset_{4 \text { ref }}\right) \frac{\partial \sigma_{\text {out }}}{\partial \emptyset_{4}} \\
& \emptyset_{1}=\left[\frac{R e_{\text {in }}}{R e_{\text {in ref }}}\right]^{a}, \emptyset_{2}=\left[\frac{L_{\text {in }} / W_{1}}{L_{\text {in }} / W_{1 \text { ref }}}\right]^{b}, \emptyset_{3}=\left[\frac{W_{2} / W_{1}}{W_{2} / W_{1 \text { ref }}}\right]^{c} \text { and } \emptyset_{4}=\left[\frac{\emptyset}{\emptyset_{\text {ref }}}\right]^{d}
\end{aligned}
$$

Where $\emptyset_{1}, \emptyset_{2}, \emptyset_{3}$ and $\emptyset_{4}$ are referred to dimensionless independent groups.

The values of $a=4.2, b=1.165, c=0.6$ and $d=2.0$ were determined in order to fit all the trend-lines in a graph and coincide at point $\sigma_{\text {out ref }}=3.7$ as shown in Figure 9 . The interrelations of dependent variable of $\sigma_{\text {out }}$ with each independent variables were linearized to obtain the best fit straight line.

$\emptyset_{1 \text { ref }}=\left[\frac{R e_{\text {in ref }}}{R e_{\text {in ref }}}\right]^{a}=1.0$

Therefore, $\emptyset_{2 \text { ref }}=\emptyset_{3 \text { ref }}=\emptyset_{4 \text { ref }}=1.0$ as well. $\frac{\partial C_{p}}{\partial \emptyset_{1}}=0.0674, \frac{\partial C_{p}}{\partial \emptyset_{2}}=-0.0885, \frac{\partial C_{p}}{\partial \emptyset_{3}}=-0.344$, and $\frac{\partial c_{p}}{\partial \emptyset_{4}}=0.4275$ represented the slopes of the corresponding lines.

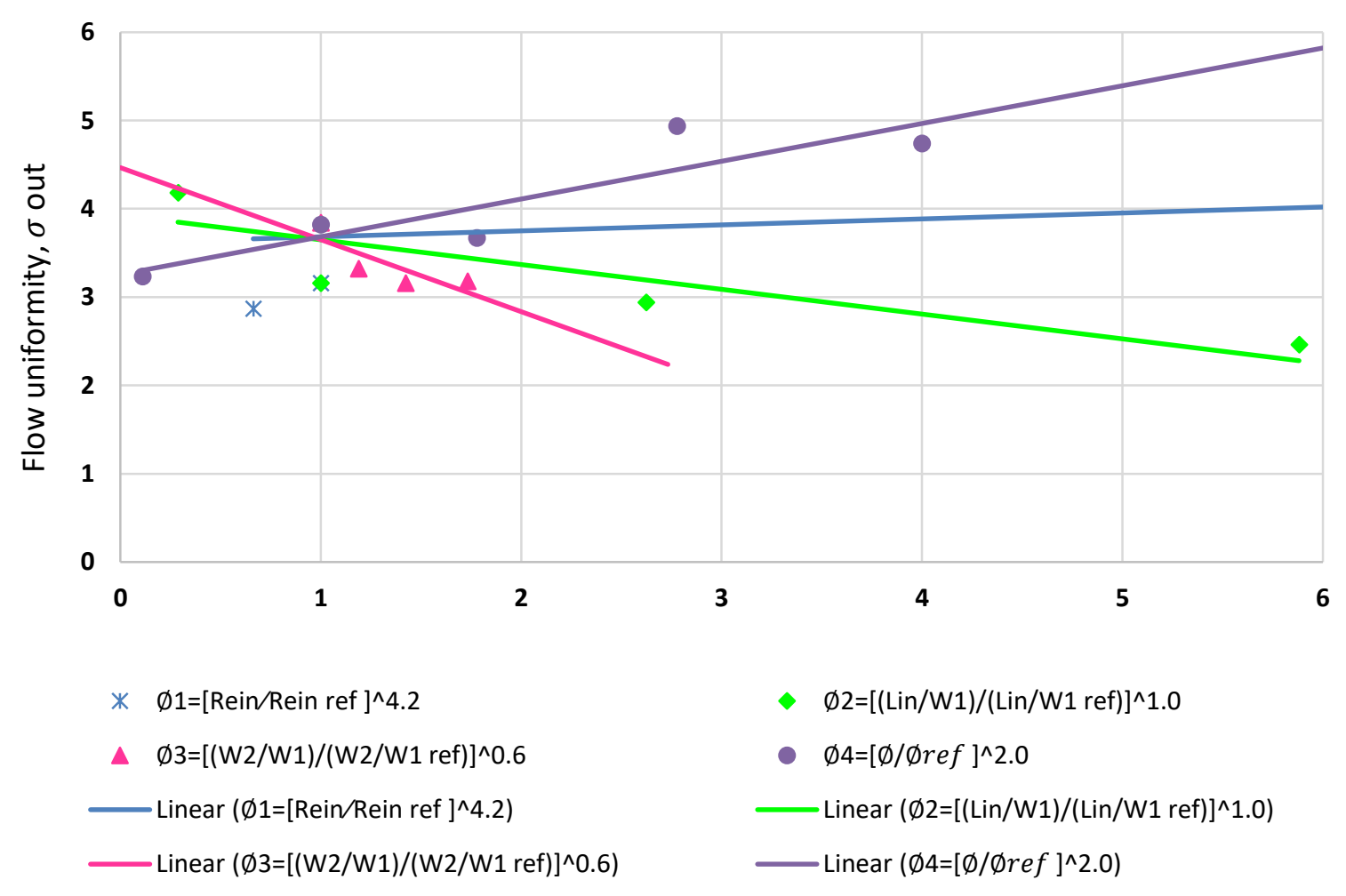

Fig. 9. Flow uniformity index, $\sigma_{\text {out }}$ of 2-D turning diffuser relatives to $\emptyset_{1}=\left[\operatorname{Re}_{\text {in }} / \operatorname{Re}_{\text {in ref }}\right]^{4.2}, \emptyset_{2}=$ $\left[\mathrm{L}_{\text {in }} / \mathrm{W}_{1} / \mathrm{L}_{\mathrm{in}} / \mathrm{W}_{1 \mathrm{ref}}\right]^{1.165}, \emptyset_{3}=\left[\mathrm{W}_{2} / \mathrm{W}_{1} / \mathrm{W}_{2} / \mathrm{W}_{1 \mathrm{ref}}\right]^{0.6}$ and $\emptyset_{4}=\left[\varnothing / \emptyset_{\mathrm{ref}}\right]^{2.0}$ 
All the constraints obtained are substituted into Eq. (12) yielding,

$$
\begin{aligned}
& \sigma_{\text {out acfd }}=3.7+\left(\left[\frac{R e_{\text {in }}}{R e_{\text {in ref }}}\right]^{4.2}-1\right) 0.0674-\left(\left[\frac{L_{\text {in }} / W_{1}}{L_{\text {in }} / W_{1 \text { ref }}}\right]^{1.165}-1\right) 0.0885-\left(\left[\frac{W_{2} / W_{1}}{W_{2} / W_{1 \text { ref }}}\right]^{0.6}-\right. \\
& \text { 1) } 0.344+\left(\left[\frac{\emptyset}{\oint_{\text {ref }}}\right]^{2.0}-1\right) 0.4275
\end{aligned}
$$

Where,

$$
R e_{\text {in ref }}=6.382 \times 10^{4}, L_{\text {in }} / W_{1 \text { ref }}=4.37, W_{2} / W_{1 \text { ref }}=1.2 \text { and } \emptyset_{\text {ref }}=90^{\circ}
$$

ACFD correlations for 2-D curved diffuser to determine pressure recovery, $C_{p}$ and flow uniformity $\sigma_{\text {out }}$ with acceptable deviation between ACFD, CFD and experimental results were developed. Table 8 shows the deviations of performance correlations.

\section{Table 8}

Deviations of performance correlations

\begin{tabular}{lll}
\hline Correlation & $C_{p \text { acfd }}$ & $\sigma_{\text {out acfd }}$ \\
\hline Deviation from experiment (\%) & 4.16 & 15.34 \\
Deviation from CFD (\%) & 18.40 & 11.23 \\
\hline
\end{tabular}

\section{Conclusion}

The effect of angle of turn on 2-D curved diffuser was successfully studied. The angle of turn of 2-D curved diffuser is proven to significantly reduce pressure recovery coefficient and increase flow uniformity distortion. The performance correlations in terms of pressure recovery, $C_{p}$ and flow uniformity, $\sigma_{\text {out }}$ have been developed. The ACFD correlations results show acceptable deviations to CFD and experimental thus reliable to be used to evaluate the performance of 2-D curved diffuser.

\section{Acknowledgement}

This research was supported in part by Universiti Tun Hussein Onn Malaysia under TIER1 Vote H172. CFD work was carried out in CFD Laboratory, Universiti Tun Hussein Onn Malaysia (UTHM).

\section{References}

[1] Gopaliya, Manoj Kumar, Piyush Goel, Sunil Prashar, and Anil Dutt. "CFD analysis of performance characteristics of S-shaped diffusers with combined horizontal and vertical offsets." Computers \& fluids 40, no. 1 (2011): 280-290. https://doi.org/10.1016/j.compfluid.2010.09.027

[2] Nordin, Normayati. "Performance investigation of turning diffusers at various geometrical and operating parameters." PhD diss., Universiti Teknologi PETRONAS (UTP), 2016. http://dx.doi.org/10.13140/RG.2.2.33037.13286

[3] Zuan, A. M. S., A. Ruwaidab, S. Syahrullailc, and M. N. Musad. "The Effect of Adding Diffuser by Experimental." Journal of Advanced Research in Applied Mechanics 14, no. 1 (2015): 18-24.

[4] Gan, Guohui, and Saffa B. Riffat. "Measurement and computational fluid dynamics prediction of diffuser pressureloss coefficient." Applied energy 54, no. 2 (1996): 181-195. https://doi.org/10.1016/0306-2619(95)00078-X

[5] Schut, S. B., E. H. Van Der Meer, J. F. Davidson, and R. B. Thorpe. "Gas-solids flow in the diffuser of a circulating fluidised bed riser." Powder Technology 111, no. 1-2 (2000): 94-103. https://doi.org/10.1016/S0032-5910(00)00245-X

[6] Deniz, Sabri. "Effects of Inlet Flow Field Conditions on the Stall Onset of Centrifugal Compressor Vaned Diffusers." In ASME International Mechanical Engineering Congress and Exposition, vol. 37254, pp. 61-74. 2003. 
https://doi.org/10.1115/IMECE2003-55221

[7] Cerantola, David. "Evaluation of Swirl and Tabs in Short Annular Diffusers." PhD diss., Queen's University, 2014.

[8] Vaz, Jerson RP, Alexandre LA Mesquita, André L. Amarante Mesquita, Taygoara Felamingo de Oliveira, and Antonio Cesar Pinho Brasil Junior. "Powertrain assessment of wind and hydrokinetic turbines with diffusers." Energy Conversion and Management 195 (2019): 1012-1021. https://doi.org/10.1016/i.enconman.2019.05.050

[9] Lindgren, Björn, and Arne V. Johansson. "Design and evaluation of a low-speed wind-tunnel with expanding corners." Flow Facility Design and Experimental Studies of Wall-Bounded Turbulent Shear-Flows 63 (2002).

[10] Calautit, John Kaiser, Hassam Nasarullah Chaudhry, Ben Richard Hughes, and Lik Fang Sim. "A validated design methodology for a closed-loop subsonic wind tunnel." Journal of Wind Engineering and Industrial Aerodynamics 125 (2014): 180-194. https://doi.org/10.1016/i.jweia.2013.12.010

[11] Fox, Robert W., and S. J. Kline. "Flow regimes in curved subsonic diffusers." Journal of Basic Engineering 84, no. 3 (1962): 303-312. https://doi.org/10.1115/1.3657307

[12] Khong, Y. T., N. Nordin, S. M. Seri, A. N. Mohammed, A. Sapit, I. Taib, K. Abdullah, A. Sadikin, and M. A. Razali. "Effect of turning angle on performance of 2-D turning diffuser via Asymptotic Computational Fluid Dynamics." In IOP Conference Series: Materials Science and Engineering, vol. 243, no. 1, p. 012013. 2017. http://dx.doi.org/10.1088/1757-899X/243/1/012013

[13] Sparrow, E. M., J. P. Abraham, and W. J. Minkowycz. "Flow separation in a diverging conical duct: Effect of Reynolds number and divergence angle." International Journal of Heat and Mass Transfer 52, no. 13-14 (2009): 3079-3083. https://doi.org/10.1016/i.ijheatmasstransfer.2009.02.010

[14] Nordin, Normayati, Zainal Ambri Abdul Karim, Safiah Othman, and Vijay R. Raghavan. "The performance of turning diffusers at various inlet conditions." In Applied Mechanics and Materials, vol. 465, pp. 597-602. Trans Tech Publications Ltd, 2014. https://doi.org/10.4028/www.scientific.net/AMM.465-466.597

[15] Huang, Lim Gim, Normayati Nordin, Lim Chia Chun, Nur Shafiqah Abdul Rahim, Shamsuri Mohamed Rasidi, and Muhammad Zahid Firdaus Shariff. "Effect of Turbulence Intensity on Turning Diffuser Performance at Various Angle of Turns." CFD Letters 12, no. 1 (2020): 48-61.

[16] Balaji, C., and H. Herwig. "The use of ACFD approach problems involving surface radiation and free convection." International communications in heat and mass transfer 30, no. 2 (2003): 251-259.

https://doi.org/10.1016/S0735-1933(03)00036-8 